\title{
XVI. Notes from the physical laboratory of University College Bristol
}

\section{Prof. Silvanus P. Thompson B.A. D.Sc.}

To cite this article: Prof. Silvanus P. Thompson B.A. D.Sc. (1879) XVI. Notes from the physical laboratory of University College Bristol , Philosophical Magazine Series 5, 8:47, 129-136, DOI: $10.1080 / 14786447908639663$

To link to this article: http://dx.doi.org/10.1080/14786447908639663

曲 Published online: 13 May 2009.

Submit your article to this journal $[\pi$

Џ Article views: 2

Q View related articles $₫$ 
sition of $\mathrm{HI}$ by $\mathrm{H}_{2} \mathrm{O}_{2}$, say*, "Comparing equivalent quantities, it had been observed that hydric chloride increases the rate of change nearly twice as much as hydric sulphate."

Ostwald $\dagger$, by a series of experiments on specific volumes arrives at the conclusion that $\frac{2 \mathrm{HCl}}{\mathrm{H}_{2} \mathrm{SO}_{4}}=1.93$.

Subsequently Mills and Hogarth $\ddagger$, after a series of experiments on the effect of hydric chloride and sulphate on lactin, considered Ostwald's result not far from the truth. Taking 80 as being the correct number for $\mathrm{H}_{2} \mathrm{SO}_{4}$, the above experiments give for the ratio $\frac{2 \mathrm{H} \mathrm{Cl}}{\mathrm{H}_{2} \mathrm{SO}_{4}}$ the value $1 \cdot 63$.

In comparing the rates of two different experiments by the equation $y(a+t)=b \mathrm{I}$ have in every case taken the ratio $\frac{b}{b^{\prime}}$ as representing the true value; but, seeing that $a$ is the time required to perform half the oxidation, $\frac{a}{a^{\prime}}$ should be equal to $\frac{b}{\bar{b}^{\prime}}$. But this is not the case (Tables I. and II.). The reason of the discrepancies is, that the value of $y$ in each caso is not the same when $t=0$. If in two experiments we calculate the times required to reduce $y$, say, from 10 to 5 units, and compare them, we get the same ratio as $\frac{b}{b^{\prime}}$.

It will be noticed that the constant $a$ is independent of the strength of the permanganate used for determining the iron.

My best thanks are due to Dr. Frankland, in whose laboratory I had the advantage of performing the above experiments.

XVI. Notes from the Physical Laboratory of University College, Bristol. By Prof. Silvanus P. Thompson, B.A., D.Sc.\$

I. On the Source of Sound in the Bell Telephone.

$T$ THE question has been at various times and in sundry 1 places discussed whether the sounds emitted by the Bell telephone, when used as a receiver of currents, are caused by molecular vibrations in the instrument, or are due to vibrations executed by the thin iron disk as a whole. The former

* Phil. Trans. 1867, p. 134.

$\dagger$ Journ. prakt. Chem. n. F. xvi. p. 419.

$\$$ Proc. Roy. Soe. vol. xxviii. p. 272.

$\$$ Comnunicated by the Physical Society, having been read at the Meeting on April 26, 1879. 
theory appears to have been started by Professor Bell himself* in order to account for the transmission of speech by instruments having very thick iron diaphragms, and by the instruments having no diaphragms at all. This view has been also upheld by the Comte Du Moncel in several communications to the learned societies of France. The other view appears to have been first distinctly put forward by $\mathrm{Mr}$. W. H. Preece, in introducing the telephone to the British Association at Plymouth in $1877 \dagger$; and it has for its most vigorous supporters M. A. Niaudetf and Colonel Navez, the latter of whom has replied more than once to points raised by M. Du Moncel. It is a view which appears also to be supported by the recent experiments of Professur Hughes.

The evidence now to be adduced, though not absolutely conclusive on the point at issue, opens out several fresh points of interest. It consists, in brief, of the results obtained by applying to the field of the telephone the experimental method of studying the so-called lines of force, originally due to Gilbert, and developed by Faraday. The details of the method followed by the present writer are identical with those described in his communication of June 23, 1878, "On Magnetic Figures," \&c., and which consists in fixing permanently onto glass plates the figures obtained by iron-filings.

The figures obtained by means of iron-filings were resorted to with the view of ascertaining whether the changes in the magnetic field of the telephone were sufficiently marked to account for the alleged motions executed by the iron diaphragm, or whether they were such as to give any support to the molecular hypothesis.

The first step was to investigate the field of a bar-magnet when one pole was placed near a thin iron diaphragm.

It was known at the outset that a thin plate of magnetic matter might be magnetized in an enormous variety of ways. The magnetism might be distributed on the two faces, or in the manner known as lamellar ; or, instead, any two points in the disk might be taken as conjugate poles ; or any number of poles might be introduced; or, as in the magnets of $M$. Duter, the magnetization might be radially distributed, the central portion having one polarity, the other polarity existing all round the circumference. De Haldat showed that a variety of irregular magnetizations might be produced by touching

* A. Graham Bell, "Researches in Electric Telephony," Journ. Soc. Telegr. Eng. 1878, p. 414, vol. vi.

+ Rep. Brit. Assoc. 1877, Plymouth, p. 13, W. H. Preece, C.E., "On the Telephone."

$\ddagger$ Téléphones et Phonographes, p. 92. 
steel plates with the pole of a powerful magnet; and the present author also found analogous effects to be produced by passing currents through steel disks. It therefore became a matter of some interest to determine the character of the magnetization of the telephone-disk.

The figures exhibited two unsuspected features :-first, that when the diaphragm is larger than the end-face of the magnet, and even when it does not touch it, the distribution of the magnetism induced in the diaphragm is partially lamellar in character, partially radial. The central portion is magnetized almost entirely normally to its plane ; the exterior portion is radially magnetized-a narrow annular region lying between these, in which the character of the magnetization is mixed. It was further observed that this neutral zone is of greater diameter when a larger magnet is employed, and that it enlarges also as the distance separating the magnet and the diaphragm is increased. It is more strongly marked as a region of separation between the central lamellar portion and the outer radially magnetized portion in the diaphragms of thin material than in those of thick. The position of this neutral annular zone is marked in fig. 1 (p. 132), which is a sectional diagram compiled from the figures produced by filings, by a point of flexure in one of the "lines of force" proceeding from the pole towards the diaphragm. The second feature noticed was that some of the outermost lines of force ran round to the front of the disk, entering it very near its circumference.

The next effect to be studied was that produced by the magnetic inductive action of a current traversing a coil of wire about the pole. For the convenience of obtaining the filing-figures upon glass plates but one turn of wire was employed, passing through holes drilled in the glass, and situated as is the coil in the Bell telephone over the pole of the magnet, the position arbitrarily found the most efficient in the construction of that instrument. In almost all modern elementary treatises on electromagnetics it is shown that the field of a plane closed circuit is equivalent to that of a lamellar magnetic shell of equal strength, or one which has an equal number of lines of force passing through the area it occupies. The result of passing the current around the pole of the magnet will therefore be, so far as the field in the plane of the coil is concerned, to increase or diminish respectively the number of lines of force due to the magnet by the number of lines of force due to the closed circuit, according as the direction of its field coincides with, or opposes that of the magnet. But the action is not so simple on the regions of the field outside the 
plane of the circuit. The direction as well as the number of lines of force may be altered, and this in a manner so complex as almost to defy calculation, especially if the mutual induction between this magnetic combination and the adjacent iron disk be taken into account. The figures obtained with filings when the current traversed the circuit in opposite directions (see figs. 2 and 3 ) show that the lines of force proceeding

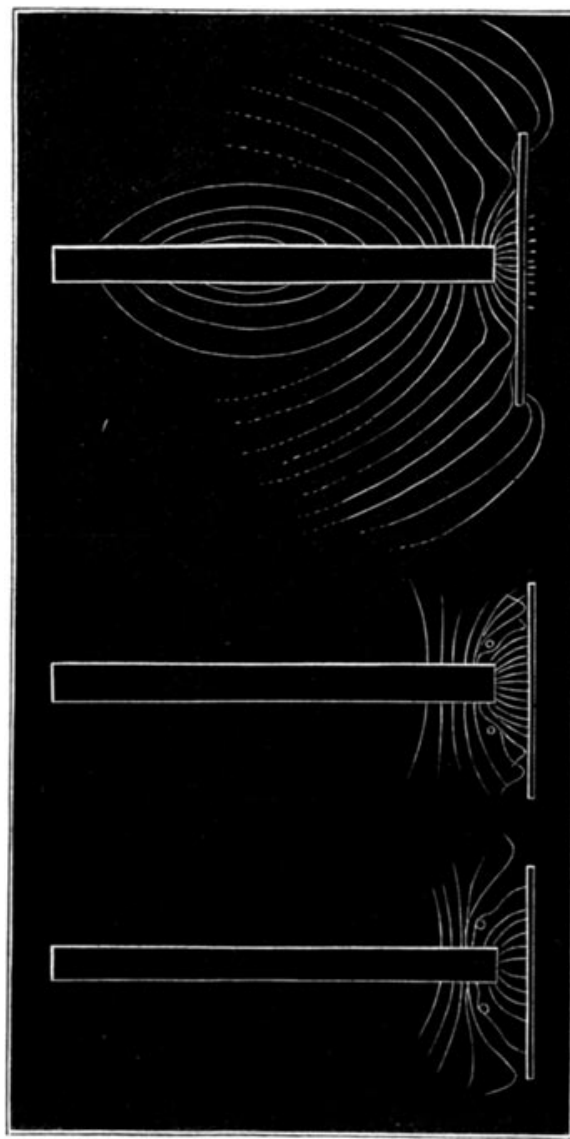

Fig. 1.

Fig. 2.

Fig. 3.

outwards from the pole were in fact thus altered both in number and in direction, and that, in addition to strengthening or weakening the field, the passage of the current had the effect of apparently thrusting the lines of filings forwards towards the iron disk or backwards from it. Moreover the region separating the two separate distributions of magnetism on the diaphragm was shifted on the passage of the current- 
being contracted in diameter when the current reinforced the magnetism of the pole, becoming enlarged when it passed in the opposite sense.

Knowing from the experiments of Joule and De la Rive that a portion of iron, when magnetized in a particular direction, grows longer in that direction and shorter in its transverse dimension, let us deduce what the effect will be on the diaphragm of a telephone of these two species of magnetization. If the mignetization were radial, the tendency would undoubtedly be, supposing the disk clamped circumferentially, to thrust the middle point of the disk backwards towards the magnet, and to give it a conical shape. If the magnetization, on the other hand, were lamellar, the tendency would be to make the diaphragm thicker, and to contract it over the area thus magnetized. In the actual case where the magnetization partakes of both characters, the two distributions being separated by a neutral zone, the tendency to each form would exist over the regions respectively affected. But the extent of these regions varies with the varying induction of the currents in the coil. Hence, while the total attraction varies, giving rise to oscillations of the diaphragm as a whole, the neutral annular line will also be continually shifting its position and predisposing the diaphragm to take up new nodal forms of vibration, thereby rendering the timbre corresponding to the complicated undulations of the currents arriving from the transmitter.

The result obtained may be regarded from another point of view. If a slight displacement of the iron disk, though unable to affect to any appreciable extent the strength of the magnetic field as a whole, alters its strength at any one point or in any narrow region, or if, even without altering the average number of lines of force in any part of the field, such a displacement shifts the position of some of the lines of force across a narrow region of the field, it may still exercise a considerable inductive action on a closed coil of wire lying in the region where the amount of shifting is greatest. For, since the induced electromotive force in a closed circuit is not proportional to the strength on an invariable magnetic field in which it lies, nor yet to all changes in its strength, but only to such changes as cause a greater or less number of lines of force to pass through the area within the closed circuit, it is evident that the inductive action will be strongest in coils of wire which lie in the region where there is most change in the direction of the lines of force. We have here the rationale of the empirical practice of the constructors of the telephone alluded to above-namely, that of using only a small coil of Phil. Mag. S. 5. Vol. 8. No. 47. Aug. 1879. 
wire, and winding it upon a narrow bobbin placed upon the extremity of the magnet.

Conversely, the passage of a very feeble current through a coil so placed will produce a greater change in the effective intensity of the magnetic field between the core and the diaphragm than would be produced by the same current traversing a similar coil in any other region of the field; for here it has its greatest power to shift the position of the neutral zone, and to alter the distribution of magnetism in the diaphragm.

It would therefore appear unnecessary to form an hypothesis of molecular vibrations in the disk to account for the emission of sounds by the instrument. Such vibrations do in fact exist; but their existence does not necessarily prove that they play any important part in the production of the sound. And it must be remembered that, so far as the disk is concerned, they take place within the narrow range of the extreme positions possible to the neutral annular zone.

Two further experiments seem to confirm the conclusion derived from the foregoing observations. If a compound diaphragm be used, consisting of concentric annuli of thin iron fixed to a stretched membrane of paper, or if a small iron disk thus fixed be employed, as in Bell's earliest experiment and in some of the experimental telephones of M. Niaudet, a curious timbre is thereby imported into the voices of speakers, though their enunciation is very distinct. A similar result is found to follow the employment of small thick diaphragms. In each of these cases the disposition favours the lamellar distribution of the' magnetism.

If, however, a compound diaphragm be employed, consisting of a number of radial pieces similarly fastened to a stretched membrane, tones are well rendered, but enunciation is not distinct. This result is also obtained when the diaphragm of iron is too large in proportion to its thickness. In these cases the greater part of the magnetism is radially distributed.

Whenever a complete theory of the telephone is framed, these are points which must be taken into account.

\section{On a new Variety of Magnetic Figures.}

De Haldat showed that it was possible to produce magnetic writing upon a steel plate by actually writing with the pointed pole of a powerful magnet, the writing being invisible until fine iron-filings were dusted over the plate. In the Physical Laboratory of University College, Bristol, a small circular saw has been found to afford a plate of suitable thickness and quality to produce good results. The latent characters remained for eight months after being inscribed. 
While experimenting with these figures, it occurred to the author to try the effect of leading the current of a powerful battery into the plate and of writing on it with the other pole. This done, fine iron-filings were dusted over the plate; and on gently tapping it the writing became legible immediately. A small thin disk of steel which thus had a current passed through its centre exhibited afterwards a magnetism distributed in small concentric rings.

\section{On Magnetic Figures for Demonstration.}

For the production of magnetic figures filings of wrought iron are usually employed, though cast iron answers fairly. Finely powdered magnetic oxide is recommended by some writers, though it does not appear that its employment is attended with any great advantage. Professor A. M. Mayer took special pains* to produce filings of even quality from specially prepared Norwegian iron; but he says nothing about the size of filings be found best suited for the purpose. Faraday made the remark $\uparrow$ that "large and also fine filings are equally useful in turn."

The anthor, desiring to obtain figures on a larger scale than usual, for purposes of class demonstration, used a number of small steel needles with success. In the case of thin elongated bodies such as these, the magnetic moment is great as compared with the mass; hence it was to be expected that filaments of fine soft iron wire would also yield a good result. Accordingly he had a quantity of fine iron wire gauze of 32 meshes to the inch cut to fragments. The filaments thus produced were scattered in the usual way by means of a pepper-box with perforated lid. The figures given by these filaments with large magnets possess very well-marked characters, and are decidedly superior to those made with ordinary filings.

IV. On the Magnetic Behaviour of fixed Iron Filings.

Having occasion to draw the attention of his students to the property of the lines of magnetic force as being at every point tangential to the position of a small freely-suspended magnet placed above them, the author, placing thus a small magnet over the filings fixed some time previously to glass, and from which the magnet producing them had been removed, noticed that they still retained their magnetic property. It then occurred to him to see whether they still possessed directive force as a whole, and found that they appeared capable of attracting and repelling a lightly suspended needle. A figure

* Vide American Journal of Science, 1872.

† 'Experimental Researches,' vol, iii. p. 398.

L 2 
produced by a single bar-magnet and fixed permanently to a slip of card by gum was suspended lightly upon a needlepoint by means of a glass cap. It set itself in the magnetic meridian, and was found capable of being deflected on the approach of a steel magnet. The fixed magnetic curves are therefore themselves magnets.

\section{Magnetic Figures of three dimensions.}

The writer has several times essayed to produce magnetic figures of three dimensions. The difficulty in producing them arises from the weight of the iron filings when unsupported, as they must be when the whole figure does not lie in one horizontal plane. With even the most powerful electromagnets the forms of the curves cannot be actually constructed in iron filings for more than a few millimetres length.

Attempts to float iron filings are also difficult, as there is no transparent liquid nearly approaching the density of iron. The writer bas tried heavy paraffins and strong solutions of mercuric iodide in potassic iodide. Better effects were obtained, however, when iron filings were employed which had previously been coated with shellac varnish, and which therefore possessed greater buoyancy. The experiment is curious ; but the difficulty of seeing across the forests of lines of filings reduces the observation to one of curiosity only.

Another process attempted consisted in plunging a small magnet into a soft paste of plaster of Paris and iron filings. The plaster shortly hardened; and then sections were cut in various directions. The figures observed, however, were poor ; and no observations were made of any additional interest as the result of the attempt.

XVII. On the Dissociation of Aniline Colours. By J. H. BICKeT, Assistant in the "Young" Laboratory of Technical Chemistry, Glasgow*.

T $N$ the course of their researches on dyeing, an account of 1 which has recently been communicated to the Chemical Society†, it was found by Professor Mills and Mr. Thomson that a dilute aqueous solution of rosaniline acetate or hydrochloride is entirely decolorized by boiling, nevertheless imparting the rosaniline salt in its normal red state to a piece of silk immersed in the heated liqued On Professor Mills's suggestion, I have made some further experiments in connexion with this subject.

* Communicated by Dr. Mills, F.R.S.

$\dagger$ 'Journal' (1879), i. p. 26. 